\title{
UN CARGO PARA EL DUQUE DE MEDINA SIDONIA: PORTUGAL, EL ESTRECHO DE GIBRALTAR Y EL COMERCIO INDIANO (1578-1584)
}

POR

\author{
LUIS SALAS ALMELA \\ CHAM (Lisboa) - EEHA (Sevilla)*
}

Este artículo descubre e interpreta la negociación que se produjo en torno a la candidatura del duque de Medina Sidonia para presidir tanto el Consejo de Indias como la Casa de la Contratación en torno a 1580. A partir de la coyuntura histórica de aquellos años, tanto para la Casa señorial como para la Corona y sus instituciones, analizamos los argumentos a favor y en contra de la idoneidad del duque para los cargos. De este modo, el rechazo de Medina Sidonia arroja nueva luz sobre el significado de aquella crucial coyuntura.

Palabras Clave: Nobleza, defensa, poder, Carrera de Indias, instituciones, armadas.

Hacia 1580 el VII duque de Medina Sidonia, don Alonso Pérez de Guzmán el Bueno, llevaba una década gobernando el estado señorial más poderoso de Castilla. Las muertes de su padre y de su abuelo, antes de que don Alonso alcanzase la mayoría de edad, habían dejado a su madre - la condesa de Nieblacomo tutora y gobernadora de la Casa señorial, cuya gestión de la herencia alaban todos los cronistas como ejemplo de prudencia y saneamiento. La primera aparición del joven don Alonso en la Corte regia se produjo con motivo de la venida de Felipe II a Córdoba, donde había convocado Cortes, ya en los últimos compases de la Guerra de las Alpujarras (1567-1570)1. Fue entonces, a sus 21 años, cuando don Alonso obtuvo el reconocimiento de su mayoría de edad, por virtud de la cual comenzaba su «reinado» sobre la herencia de sus mayores. Una

\footnotetext{
* Este artículo se enmarca en el proyecto «Las fronteras y sus ciudades» [HUM2007-64126].

1 Fernández Álvarez, 2002: 120-132.
} 
herencia que no sólo se componía de una amplia jurisdicción sobre una muy considerable extensión de tierras repartidas por las actuales provincias de Cádiz, Huelva y Málaga, sino también de una tradición vindicativa de servicio a la Corona que había sido capaz de elevar a la categoría de mito al fundador del linaje - don Alonso Pérez de Guzmán, llamado «El Bueno»- por su hazaña en la defensa de Tarifa. Sin embargo, por encima de cualquier otra consideración, lo que cimentaba la primacía del poder de esta Casa ducal frente al resto de la nobleza castellana era la posesión de la ciudad de Sanlúcar de Barrameda y su aduana, primacía que se quebró precisamente en 1641, cuando la implicación del IX duque en un caso de conjura contra Felipe IV supuso la pérdida del señorío sobre esta villa. En otras palabras, la dimensión fiscal del poder de los Medina Sidonia constituía su principal baza precisamente por la ubicación de sus estados, en la puerta de Castilla hacia América ${ }^{2}$.

Todo aquel poder sustentado en el privilegio encontraba buena parte de su solidez, en efecto, en el armazón legitimador que proporcionaba la reivindicación histórica de la Casa ducal como fiel servidora del bien común y, por ende, de la Corona. Por esta causa, tras la minoridad de don Alonso, durante la cual los Medina Sidonia habían perdido protagonismo político, pareció oportuno que el nuevo duque buscase la forma de recuperar la iniciativa en este terreno como forma de revitalizar el prestigio que su linaje atesoraba ${ }^{3}$. Ahora bien, la carrera de servicio de un duque de Medina Sidonia tenía sus propias peculiaridades, como vamos a poder comprobar en estas páginas, basadas sobre todo en su capacidad de actuar sobre un sector tan estratégico para la Monarquía como era el comercio de Indias, capacidad que está en la base misma de la influencia de que hacían gala los Medina Sidonia en la Corte regia.

Por otro lado, aquella carrera de servicio comenzó su andadura en un momento clave para la Monarquía de Felipe II, caracterizado por unas circunstancias geoestratégicas que coadyuvaron a otorgar mayor protagonismo al área de influencia prioritaria del duque de Medina Sidonia: la Baja Andalucía. En efecto, tras la calma que sucedió a la batalla de Lepanto, la amenaza del poderío turco volvió a hacerse palpable en el interés mostrado por los otomanos en llevar sus dominios hasta las costas atlánticas, aunque fuese mediante bastiones o puntos fuertes ${ }^{4}$. En este sentido, la independencia del territorio marroquí respecto de la tutela de la Sublime Puerta se convirtió en materia de vital im-

2 Salas Almela, 2008: passim.

3 Así, la venida de Felipe II a Andalucía ofreció la primera ocasión de servicio a don Alonso, que se plasmó en la implicación de sus vasallos y bienes, en la última y más cruenta etapa de la Guerra de las Alpujarras. Álvarez de Toledo, 1985, tomo I: 77-155.

4 Sancho de Sopranis, 1953: 7-77. 
portancia para la Monarquía Hispánica y Portugal ${ }^{5}$. Las voces de alarma que se sucedieron en el área del Estrecho por la irrupción de escuadras de galeras turcas o por la presencia de embajadores del sultán en alguna de las cortes marroquíes iban más allá del temor a esporádicas capturas de buques mercantes, ya de por sí preocupantes. Por otra parte, la aventura africana del rey don Sebastián de Portugal abrió un período de incertidumbre que aumentó mucho el grado de interés y atención sobre la zona del Estrecho de Gibraltar ${ }^{6}$. El resultado de la llamada Batalla de los Tres Reyes - Alcazarquivir, 1578 - se tradujo en una enorme actividad diplomática y militar en la Baja Andalucía en sus dos fronteras, tanto con el reino de Portugal, a partir de entonces en disputa, como en la frontera marítima con África ${ }^{7}$. Así, estos frentes de atención - frontera africana, vigilancia sobre el Algarve y control del comercio indiano- marcan los parámetros sobre los que los Medina Sidonia procuraron articular su colaboración con la Corona en el medio siglo siguiente.

\section{LAS SECUELAS DE AlCAZARQUivir}

La crisis de autoridad en el territorio marroquí a que dio lugar el desastre de Alcazarquivir provocó de inmediato el interés de los dos grandes imperios mediterráneos. El turco volvió a mostrar su interés por someter políticamente a algún tipo de control al reino de Fez, lo que le hubiera otorgado su ansiada frontera Atlántica, pese a que en Marruecos los centros de poder - contrariamente a lo que sucedía en el resto del mediterráneo magrebí - se encontraban ubicados en el interior ${ }^{8}$. Para ello el sultán puso en marcha una intensa presión diplomática y militar sobre las debilitadas autoridades marroquíes. Ahora bien, la paz firmada con la Monarquía de Felipe II tras la batalla de Lepanto - que preveía que sólo una agresión abierta a un aliado firme del adversario podía justificar el recurso a las armas - complicaba la capacidad de maniobra de uno y otro imperio en Marruecos, al obligarles a trabar acuerdos estables con alguno de los reinos marroquíes para poder legitimar una intervención directa $^{9}$. En este contexto, desde 1579 en adelante, sobre la promesa de entrega

5 Rodríguez Salgado, 1992: 395-413.

6 Noticia que al parecer llegó con cierto grado de seguridad a la Corte de Felipe II por vía del duque de Medina Sidonia. Carta de 18 de agosto de 1578, en Riba García, 1959: 185-186.

7 Braudel denominó a este conjunto de episodios giro atlántico. Braudel, 1993: vol. II: 703-706; luego seguido, entre otros muchos, por Kamen, 1998: 257.

8 Fez y Marrakech, como ya señalaran los Bennassar. Bennassar, 1989: 454.

9 Don Juan de Silva — futuro conde de Portalegre - redactó un memorial con los argu- 
de Larache - enclave marroquí situado en la boca atlántica del Estrecho- a cambio de obtener ayuda en la defensa de su trono, Felipe II inició una larga y tortuosa negociación con el Jerife de $\mathrm{Fez}^{10}$. En realidad, la importancia prestada entonces a Larache se basaba en el temor al turco, cuyo acceso al océano hubiera amenazado las rutas atlánticas, al tratarse de un puerto capaz de albergar en su rada una potente escuadra de galeras ${ }^{11}$.

La situación era, por tanto, propicia para que Medina Sidonia pusiese sus capacidades al servicio de Felipe II con el doble objetivo de reforzar su propio poder por medio del ejercicio del servicio y de legitimar sus múltiples privilegios. De hecho, toda la negociación de Larache tuvo en el duque un referente esencial de la política magrebí de Felipe II, tanto en el plano diplomático como en el militar. Así, por ejemplo, el embajador del rey católico en Fez, Pedro Venegas de Córdoba, dependió en todo momento para su gestión de las órdenes transmitidas por o recibidas directamente de don Alonso. Por su parte, los planes que se prepararon para asumir el traspaso de soberanía de la plaza contemplaron en todo momento el mando personal del duque en la expedición militar. Así, en el verano de 1581, cuando la operación parecía inminente, el duque llegó a embarcarse y recorrer la costa andaluza al mando de 17 galeras, con orden de limpiar de corsarios la franja entre San Vicente y Gibraltar para garantizar el resultado ${ }^{12}$.

Ahora bien, como decíamos, hay que inscribir este episodio en la crisis sucesoria portuguesa para entender cabalmente por qué Felipe II aceptó el protagonismo del duque y qué podía ofrecer don Alonso. En primer lugar debemos señalar que al temor a una posible salida turca a las costas atlánticas se sumó la urgencia de hacer más patente la presencia castellana en un área en la que el predominio portugués por medio de su red de presidios era evidente. Muerto don Sebastián y abierta la puerta a una previsible sucesión de Felipe II en el reino luso, esa presencia castellana en el norte de África cobró un nuevo sentido que se plasmó en una doble iniciativa: por un lado, había que atraer la fidelidad de los presidios portugueses a la causa de Felipe II, haciéndoles patente

mentos que podría esbozar Felipe II para la toma de Larache en junio de 1583. Colección de Documentos Inéditos para la Historia de España (en adelante CODOIN), tomo 43, 448-453.

10 Buena parte del epistolario sobre la negociación de Larache en aquellos años se publicó en CODOIN, tomo 27.

11 Algunas informaciones sobre la operación, aunque enfocadas ante todo a demostrar la supervivencia de don Sebastián, en Álvarez de Toledo, 1985, tomo I: 163-174.

12 Las noticias del embarque de Medina Sidonia en cartas de 3, 8, 13, 22 y 31 de julio; 1, 2 y 10 de agosto de 1581, Archivo Ducal de Medina Sidonia (en adelante, ADMS), 2.398, passim. Ver también, Álvarez de Toledo, 1985: tomo I, 167-168; Cabanelas, 1960: 19-53 y Cabanelas, 1974: 7-27. 
que cualquier dilación en la resolución del problema sucesorio repercutiría en el aumento de su propia inseguridad; por otro, convenía al mismo tiempo poner en juego una presencia militar castellana capaz de intimidarles en caso de duda. De hecho, se trataba de un equilibrio de persuasión y amenaza militar similar al que se utilizó en el territorio ibérico del reino portugués, si bien la diferencia radica en que los presidios lusos vivían en dependencia casi completa de la metrópoli, por lo que una alteración de los canales de suministro amenazaba su propia supervivencia. De hecho, esta debilidad justifica la prontitud con la que los presidios portugueses aceptaron la candidatura del Rey Católico, que llevó a Medina Sidonia a preparar, ya en agosto de 1580, la proclamación de Felipe II como rey de Portugal en dichas plazas ${ }^{13}$.

De modo similar, ciertas secuelas de la batalla de Alcazarquivir debían ser abordadas con la vista puesta en la candidatura filipina al trono luso. Así, por ejemplo, la repatriación del cuerpo del rey don Sebastián debía ser organizada con sumo cuidado para no herir susceptibilidades ni generar dudas, por lo que se dieron órdenes concretas a Medina Sidonia en este sentido. También resultaba capital el tratamiento que se dispensase a la nobleza portuguesa superviviente de la batalla, tanto a la hora del rescate como en la preparación de su traslado a la península, tarea que de nuevo asumió Medina Sidonia, que puso a disposición de esta operación sus contactos en Marruecos, sus puertos y su propio palacio sanluqueño. Según se desprende de la correspondencia del duque con Felipe II, en este aspecto era don Alonso quien fue tomando una iniciativa que el rey aprobaba y agradecía a posteriori ${ }^{14}$. Uno de los supervivientes que se benefició de la ayuda y de la hospitalidad del duque fue precisamente el prior de Crato, don Antonio ${ }^{15}$. Otro de los representantes más conspicuos de aquel selecto grupo de cautivos fue el duque de Barcelos, que venía acompañado de algunos notables, entre los que figuraba su primogénito —el conde de Vimioso_- acompañado por don Luis de Alemcastre, Jorge de Quirós y Baltasar Polo. Tengamos en cuenta que por las fechas en que estos señores pasaron por Sanlúcar se estaba votando en las cortes portuguesas de Santarém, a propuesta del anciano rey don Enrique, la sucesión de Felipe II, por lo que la llegada de los supervivientes podía llegar a alterar el apoyo al Habsburgo que

13 Así, el duque de Medina Sidonia sugirió al monarca que fuesen los corregidores de Cádiz, Jerez y Gibraltar los que acudiesen a tomar posesión de ellas en nombre de Felipe II. Carta de Felipe II a Medina Sidonia, 22 de agosto de 1580, ADMS, leg. 2.398.

14 Labor que se prolongó al menos hasta principios de 1582, cuando estuvo en Sanlúcar el marqués de Favara, que no dejó de causar algún problema al duque, a cuyo mayordomo, don Pedro de Abeancos, llegó a amenazar de muerte el portugués. Riba García, 1959: 269-271.

15 Fernández Álvarez, 2002: 247. 
se esperaba obtener sin mucha resistencia de los brazos nobiliario y eclesiástico. En ese sentido, Medina Sidonia debía actuar con mucho tacto, sondeando intenciones y regalando con todo tipo de festejos y agasajos a sus huéspedes. Así, en carta de 9 de enero de 1580, Felipe II aprobó la intención de Medina Sidonia de entretener la partida de Barcelos, a la espera de la evolución de los acontecimientos. Además, aunque los portugueses debían gozar de entera libertad de movimientos, el Rey Católico aplaudió sin reservas la iniciativa de don Alonso de usar su buena amistad con el conde de Vimioso para sondear las preferencias del séquito de Barcelos, de modo que se pudiese juzgar la conveniencia de acelerar o entorpecer su marcha a Madrid o a Lisboa ${ }^{16}$.

Sin embargo, al morir don Enrique de Portugal sin haber logrado cerrar la pacífica sucesión del reino en Felipe II, éste comenzó a preparar la campaña militar que asegurase su coronación ${ }^{17}$. A Medina Sidonia, como señor más importante de la Baja Andalucía, se le asignó un distrito militar con carácter tanto ofensivo como defensivo que se extendía a lo largo de la frontera del reino de Sevilla - entre Ayamonte y la actual provincia de Badajoz. Sin embargo, también en este terreno el duque se anticipó a las órdenes regias, al menos en sus territorios, levantando tropas y cuidando las defensas en sus muchos lugares fronterizos con Portugal. Felipe II aceptó de buen grado las disposiciones del duque, como pone de manifiesto que el mismo día en que se remitió aprobación de lo que había dispuesto el duque en su estado, se le encargase en otra misiva hacer lo propio en todo el distrito puesto bajo su mando. Por lo demás, en lo que atañe al aspecto ofensivo del distrito, se trataba de anticiparse a la contingencia de que el brazo popular de las cortes portuguesas no se aviniese al reconocimiento de los derechos de Felipe II, es decir, de que el «el negocio viniese a necesidad de las armas» ${ }^{18}$.

16 Nada sabemos de cómo se desarrolló aquella recepción. En cambio, sí sabemos que Vimioso, «herido en dos partes», fue el único noble que siguió a don Antonio en su huida hacia Aveiro, una vez derrotado el prior de Crato. Ver, cartas de Felipe II a Medina Sidonia de 9 de enero de 1580 y 1 de septiembre de 1580. También Felipe II aprobaba el consejo de Medina Sidonia de no enviar directamente la noticia sobre la muerte de su hijo al duque de Bragança y menos de hacerlo por mano de don Cristóbal de Moura, por la poca correspondencia que había entre ambos. En ADMS, leg. 2.398; los preparativos del paso de Barcelos por tierras ducales en carta de 13 de noviembre de 1579, ADMS, leg. 948.

17 Ésta fue la explicación esgrimida por Felipe II a Medina Sidonia en carta de 19 de febrero de 1580 cuando le pidió su colaboración. ADMS, leg. 2.398. Algunas noticias sobre la participación del duque en Álvarez de Toledo, 1985, tomo I: 139-146.

18 Así, Felipe II aprobaba lo dispuesto por el duque en carta de 3 de febrero de 1580. ADMS, leg. 2.398. Ver también Carta de Felipe II al marqués de Gibraleón, 19 de febrero de 1580, Archivo Histórico Nacional-Nobleza (en adelante AHN-N), Osuna, c. 227, d. 8. 
En su actuación en el sur de Portugal, el duque dio prioridad a la estrategia de mostrar a la nobleza lusa las ventajas que le esperaban de aceptar la candidatura filipina ${ }^{19}$. Por el contrario, con el brazo popular sugería que, para evitar la eventualidad de la intervención armada, el mejor modo de ganarse los ánimos sería aplicar «justicia y más justicia», en lugar del fácil recurso a la concesión de mercedes, las cuales acababan teniendo, según él, un efecto contrario al deseado. En el fondo, la estrategia que proponía Medina Sidonia era tan pacífica como la que en Madrid proponía el conde de Portalegre, pero cargar el acento en el rey justiciero antes que en el dadivoso tenía interesantes implicaciones a la hora de mostrar el aprecio por el real servicio ${ }^{20}$. Lo cierto es que el duque se mostró muy activo a favor de la candidatura filipina, tanto en las negociaciones concretas como en la difusión de los textos propagandísticos publicados por Felipe II en Badajoz ${ }^{21}$. Cumpliendo este cometido, cuando el prior de Crato se perfiló como rival del Habsburgo, Medina Sidonia señaló a los eclesiásticos en general como el principal foco de oposición. «Vuestra Majestad crea [advirtió el duque] que he entendido ahora cosas de ellos terribles y que conviene a Vuestra Majestad tanto el dar medios con ellos como con don Antonio». Para atajar aquel foco desestabilizador, don Alonso propuso al rey que hiciese mudar a los más señalados opositores del clero luso a algunos conventos de sus órdenes en Castilla ${ }^{22}$.

Ahora bien, las gestiones pacíficas no fueron suficientes y hubo que entrar con ejércitos por varios puntos en Portugal para derrotar a los partidarios de don Antonio. Como jefe militar de la frontera sur - con el cargo ad hoc de Capitán General de la Caballería e Infantería de Andalucía- Medina Sidonia se puso al mando de las tropas levantadas en su distrito y se le ordenó, a fines de marzo de 1580, prevenir todo para entrar en Portugal ${ }^{23}$. En efecto, don Alonso entró en Portugal durante aquella jornada al frente de un ejército, si bien, al contrario de lo que sucediera con la toma y saqueo de Lisboa al mando del duque de Alba, las operaciones en el Algarve no necesitaron del uso directo de las armas, que más bien tuvieron un efecto de intimidación que en ningún caso debe ser despreciado. En conjunto, la contribución personal del duque a la jor-

19 Fernández Álvarez, 2002: 248.

20 Bouza, 1998: 478.

21 Bouza, 2000: 39-60, 59.

22 Carta de Medina Sidonia a Felipe II, 9 de junio de 1581, British Library (en adelante BL), Add. 28.370, fols. 48r-51v.

23 Carta de Felipe II a Medina Sidonia de 22 de marzo de 1580, ADMS, leg. 2.398. Aquel ejército había sido levantado bajo sus órdenes. Así, Felipe II pidió a Medina Sidonia que siguiera presionando a las ciudades de Carmona y Puerto Real para que siguiesen el ejemplo de Jerez, que ya había levantado 200 infantes. 13 de marzo de 1580, ADMS, leg. 2.398. 
nada se concretó en tres materias. Primero, en el elevado número de vasallos de sus estados que le acompañaron, que alcanzaron la cifra de 3.870 hombres $^{24}$. Además, de sus armerías salió gran cantidad de artillería que fue prestada para los diversos frentes de la campaña, poniendo una vez más de relieve el potencial militar que atesoraban algunos grandes nobles ${ }^{25}$. Por último, hay que mencionar el esfuerzo económico de algunas de sus villas, que prestaron elevadas sumas al duque, aunque parece que después les fueron devueltas ${ }^{26}$. Como primera recompensa, don Alonso, que asistió a la coronación de Felipe II en Tomar, recibió la orden del Toisón de Oro $^{27}$.

Por otro lado, cuando, derrotado don Antonio, hubo que recurrir a espías para tratar de capturarle, Medina Sidonia también tomó parte activa, buscando la mediación de Mateo Vázquez para hacerse escuchar por Felipe II. En este sentido, el duque propuso fórmulas para peinar los territorios que habían sido favorables al prior de $\mathrm{Crato}^{28}$. Sin embargo, el duque no era el único que estaba interesado en capturar al opositor, sino que se desató una verdadera carrera para apresarlo. En carta a Medina Sidonia, don Lorenzo de Silva — uno de sus contactos portugueses en Lisboa - le tranquilizaba respecto a los otros participantes en la búsqueda:

En cuanto a lo que Vuestra Excelencia dice que nos han de ganar por la mano me río y Vuestra Excelencia haga lo mismo, porque ha ocho meses que cada día dicen esto a Su Majestad y le prometen grandes esperanzas ${ }^{29}$.

El duque estaba sin duda interesado en dar aquella satisfacción al rey usando sus contactos en Portugal y demostrar que podía llegar a ser muy útil para la conservación del reino luso. Apuntarse ese tanto era una baza que, en medio de un clima de desconfianza general hacia la fidelidad de los portugueses a la causa de Felipe II, cobraba un valor extraordinario ${ }^{30}$. En cambio, el fracaso en

24 Sabemos de su regreso a Sanlúcar por la carta en la que Felipe II se felicitaba de tenerle allí por la falta que hacía su autoridad para el apresto de los buques. Fechada en Almada a 15 de junio de 1581, ADMS, leg. 2.398. Una relación de los hombres entregados por cada población se encuentra entre los papeles del año 1581, aunque sin fecha.

25 Felipe II, en carta de 11 de enero de 1581, aseguraba al duque que le sería devuelta toda la que prestó al tercio de Sancho Dávila y que éste llevó a Porto, ADMS, leg. 2.398.

26 Según una nota de archivo del siglo XVIII, Huelva prestó al duque 987.342 maravedíes para los gastos de la guerra de Portugal, aunque el documento no se conserva. Fechada en 1582, ADMS, leg. 682.

27 Álvarez de Toledo, 1985, tomo I: 151.

28 Carta de 20 de mayo de 1581, BL, Add, 28.370, fols. 19r-21v.

29 Añadía acusaciones de traición al duque de Bragança. Santarém, 23 de mayo de 1581, BL, Add, 28.370, fols. 26r-29v.

30 Riba García, 1959: 244-245. 
que quedaron al fin los esfuerzos de Medina Sidonia - que se sumaron al fiasco que resultó su amistad con el conde de Vimioso, a la postre fiel antoniano-_, frustraron esta posibilidad ${ }^{31}$. De todos modos, el rey no sólo no reprochó al duque que no hubiera tenido éxito, sino que admitió que, de haber seguido los consejos de don Alonso desde el principio, el prior de Crato hubiera sido capturado $^{32}$. Fracaso relativo, pues, para el duque, toda vez que sus desvelos obtenían el oportuno reconocimiento regio.

\section{«HALLAR EL YERMO EN ESTA PLAZA DEL MUNDO»}

De hecho, ante tanta actividad y servicio de don Alonso, Felipe II se sintió obligado a recompensarle adecuadamente con la concesión de un cargo de gran responsabilidad y muchas posibilidades de demostrar su «valía», como era la Gobernación y Capitanía General del estado de Milán, vacante desde la muerte del marqués de Ayamonte, tío del propio don Alonso. En tales términos, al menos, se lo transmitió el cardenal Granvela a Medina Sidonia en carta de 8 de septiembre de $1580^{33}$. Tanto aquella comunicación oficial como las inmediatamente posteriores hicieron referencia a la urgencia con la que debía organizar el duque su partida hacia Milán, donde al parecer había ciertos temores de que la ausencia de un gobernador estuviese propiciando algún movimiento de oposición al dominio hispánico ${ }^{34}$. El nombramiento formal del

31 Los puntos propuestos por el duque en mayo de 1581 y las respuestas del rey y Vázquez en Riba García, 1959: 246-248. Al parecer, los avisos de Medina Sidonia sobre la huida de don Antonio a las Terceras los recibió Felipe II de su mano. Carta del rey a Medina Sidonia agradeciéndole la información de 18 de abril de 1581, ADMS, leg. 2.398.

32 En esta misma carta, Felipe II sugería que Medina Sidonia llevase consigo a un fraile portugués, cuando acudiese a su puesto en Milán, un tal fray Simpliciano, para que le ayudase desde allí a sondear los contactos de don Antonio en Francia. Este fraile, del que sin duda Medina Sidonia había hablado al rey como posible informador, no tardaría más que un par de meses en ser buscado como opositor a Felipe II. 5 de junio de 1581, BL, Add. 28.370, fols. 44r-45v. En carta de 1 de agosto, Felipe II comunicaba a Medina Sidonia que el tal fraile había escapado cuando se le mandó prender por hablar «demasiado suelto» en Santarém. AMDS, leg. 2.398.

33 En palabras de Granvela de 4 de octubre, Milán era el lugar donde «baten las cosas de la guerra». Ambas cartas en ADMS, leg. 2.398. Recordemos que Granvela llevaba años sirviendo en puestos clave a Felipe II y sobre todo ejerciendo de asesor sobre asuntos italianos al embajador en Roma y en el gobierno de Nápoles. Toda aquella experiencia italiana, sumada a la previa adquirida en los Países Bajos, provocaron su llamada a la Corte por Felipe II para asesorarle más de cerca. Ver Martínez Millán y De Carlos Morales, C.J., 1998: 457-459.

34 El primer apremio para que se disponga data de octubre de 1580. ADMS, leg. 2.398. 
duque como gobernador data de mayo de 1581 y en él Felipe II, tras apelar a la tradición de servicio del linaje de los Pérez de Guzmán, resaltaba los recientes servicios de don Alonso en la crisis portuguesa ${ }^{35}$.

Aquel nombramiento parece que no satisfizo en exceso al duque ${ }^{36}$, aunque Medina Sidonia no tardó mucho en responder a la primera comunicación de Granvela mostrando una gratitud que le llevaba a estar dispuesto a abandonar todos sus «importantes negocios» por acudir al servicio de su rey ${ }^{37}$. Por aquel entonces Medina Sidonia se hallaba, en efecto, preocupado por varios asuntos importantes que afectaban a su patrimonio. Destaca sobre todo la aparición en Sanlúcar del primer visitador general del comercio atlántico por cuenta regia - el licenciado Torregrosa - cuya misión era reformar un sistema de aduanas que había permitido al duque mantener una notable autonomía fiscal en su puerto. Además, en noviembre de 1581 se hizo pública una sentencia contraria a Medina Sidonia en otro pleito que afectaba mucho a su herencia - en concreto, a varias dehesas en Jimena y al largo contencioso sobre la sal. Tan grave era el asunto que don Alonso recibió las condolencias de Mateo Vázquez y hasta del propio Felipe II. Eso sí, la solidaridad del rey - transmitida por medio del secretario Gabriel de Zayas - no dejaba de mostrar cierto asombro por el hecho de que el duque se mostrase dispuesto a pagar 400.000 ducados para zanjar el pleito ${ }^{38}$.

En todo caso, tras la confirmación del nombramiento, Medina Sidonia comenzó a prepararse para acudir a Milán, prevenciones que llegaron a estar tan avanzadas como para haber permitido de hecho la marcha del duque ${ }^{39}$. Sin embargo, la creciente actividad de Medina Sidonia en las materias militares y diplomáticas en la Baja Andalucía fueron retrasando su partida ${ }^{40}$. Si en un principio fueron los asuntos de la incorporación portuguesa la excusa para pospo-

35 Firmada en Tomar a 18 de mayo de 1581, BL, Add. 16.176, fols. 280r-283r.

36 Thompson, 1969: 214.

37 En palabras de Granvela, que recogió los términos usados por el duque para alabar su abnegación en la referida carta de 4 de octubre de 1580 .

${ }^{38}$ La suma a la que se refiere Zayas aumenta en 100.000 ducados el monto de la concordia, que al fin fue ratificada en 300.000 ducados. Lisboa, 11 de diciembre de 1581, ADMS, leg. 2.398 .

39 Así, Felipe II informó a Medina Sidonia de ciertos problemas particulares de la política milanesa (en carta de 24 de febrero) y le envió unas instrucciones (19 de abril de 1581). Ambas en ADMS, leg. 2398. Por su parte, el duque preparó su alojamiento en Milán y redactó unas instrucciones para la duquesa sobre el cuidado y gobierno de los estados en su ausencia. Fechadas en 1581, AMDS, leg. 950.

40 El rey remitió a Medina Sidonia varias copias de cartas enviadas a las autoridades milanesas, desde el castellano - Sancho de Padilla-, hasta el Consejo Secreto, pasando por el Tribunal de Cuentas. Todas ellas de fecha 27 de marzo de 1581. ADMS, leg. 2.398. 
ner el viaje a Italia, la nueva promesa del jerife de Fez de entregar Larache fue el argumento que, en segundo lugar, retuvo al duque en sus estados. De hecho, resulta llamativa la forma en la que se alternan los avisos sobre la urgencia del viaje a Milán con el creciente número de responsabilidades que acumulaba Medina Sidonia, tanto por encargo regio como asumidas por el duque por propia iniciativa ${ }^{41}$. En el verano de 1581 fue un nuevo aviso de presencia de turcos en el Estrecho con la intención de tomar Larache lo que acabó con aquella inusual duplicidad: el 8 de julio de 1581 Felipe II optó por relevar temporalmente a Medina Sidonia de la gobernación de Milán ${ }^{42}$. La interinidad de este relevo, que se justificó por la necesidad que había en Milán de un representante directo de la autoridad regia, cabe entenderla como simple recurso retórico para salvaguardar el principio de autoridad del monarca sobre la decisión de enviar al duque a Milán ${ }^{43}$. No sería sin embargo hasta el 13 de enero de 1582 cuando Felipe II acabase por buscar una salida estable a la situación. El encargado de comunicar la noticia al duque fue Mateo Vázquez:

En lo que toca a la ida a Milán, Su Majestad, habiendo oído atentamente lo que el padre fray Vicente ha muy bien representado y yo también le he dicho, se ha contentado de excusar a Vuestra Excelencia la jornada, pues no faltará por acá en qué servir Vuestra Excelencia a Su Majestad y podría ser que en cosas de aquí, pero quiere Su Majestad que por ahora no diga a nadie esta resolución porque así conviene ${ }^{44}$.

La negociación que desembocó en este relevo tiene múltiples componentes. Por un lado, si bien es cierto que los pleitos que el duque llevaba entre manos eran importantes para su estado, lo cierto es que la reticencia de don Alonso en aceptar la gobernación de Milán se explica más bien por el hecho de que se trataba de un puesto que para él resultaba una forma de ostracismo políti$\mathrm{co}^{45}$. Parece descartado que el problema radicase en que Medina Sidonia no estimase el cargo acorde con la grandeza de su Casa, ya que de hecho gustó

41 El 19 de junio de 1581 le fue remitida la nueva cifra que se usaría para las materias de Milán y se le encomiaba que partiese de inmediato. ADMS, leg. 2.398.

42 ADMS, leg. 2.398.

43 Se había advertido a Medina Sidonia sobre los problemas que estaban causando ciertas extralimitaciones jurisdiccionales del cardenal Borromeo, a la sazón arzobispo de Milán. Felipe II a Medina Sidonia, Elvas, 24 de febrero de 1581, ADMS, leg. 2.398.

44 Lisboa, 13 de enero de 1582, ADMS, leg. 2.398. Todavía en 1 de febrero, Vázquez recordó al duque: «El padre fr. Vicente ha cumplido con mucho amor a Vuestra Excelencia y gran prudencia la comisión que se sirvió de darle. A él me remito». Ibidem.

45 Así lo hace Martínez Millán al aludir al nombramiento de Alba para tal ocupación en la década de 1550. En Martínez Millán, 1992: 173. Ver también Álvarez-Ossorio Alvariño, 2001: passim. 
acompañar su titulación con la referencia a la gobernación milanesa el tiempo que nominalmente la gozó. Así lo demuestra una breve respuesta de don Juan de Idiáquez al duque, quejoso éste al parecer de que en algún documento oficial se le hubiese omitido el título de gobernador. El secretario, algo irónico, apostilló: «juntará Vuestra Excelencia tantos [títulos] a ése, placiendo a Dios, como merece su valor y deseamos sus servidores ${ }^{46}$. La referencia de Idiáquez indica, por lo demás, que estaba al tanto de las aspiraciones de don Alonso ${ }^{47}$.

El momento para pretender favores regios era, desde luego, el adecuado, por lo que un alejamiento prolongado de Sanlúcar fue visto por Medina Sidonia como la pérdida de una ocasión con grandes posibilidades de negociar una mayor recompensa por sus desvelos ${ }^{48}$. De hecho, Medina Sidonia estaba trabajando para obtener algún cargo de autoridad y prestigio sobre una de las tres áreas esenciales de su interés: Portugal, el atlántico andaluz y la navegación oceánica. La primera responde a la coyuntura abierta por la incorporación del reino a la Monarquía de Felipe II, que ofrecía una amplia gama de posibles ocupaciones en la gobernación portuguesa. De hecho, la carta de Mateo Vázquez que acabamos de citar aludía a «cosas de aquí» en las que servir, un aquí que en 1582 significa Lisboa, capital de un reino en el que Medina Sidonia era muy bien considerado ${ }^{49}$. Gabriel de Zayas fue esta vez más explícito. En pleno proceso de diseño del aparato virreinal, cuya primera cabeza parecía ya con claridad que iba a ser el Cardenal Archiduque Alberto de Austria ${ }^{50}$, se pensó en Medina Sidonia para quedar junto a él «con el puesto y mano que es razón». Zayas suplicaba en consecuencia al duque «no lo rehúse Vuestra Excelencia, pues sería lo mismo que estar en su casa» ${ }^{51}$. En varios puntos el secretario daba en el blanco. Primero, señalando las posibilidades que aquel cargo otorgaba al duque para ejercer su autoridad como era razón, es decir, contando con la favorable acogida de sus contactos portugueses, en los que se sostenía

46 Lisboa, 23 de noviembre de 1581, ADMS, leg. 2.398.

47 Según Santiago Martínez, Idiáquez fue uno de los miembros de la Academia del duque de Alba. Son interesantes las referencias que ofrece sobre su actividad cortesana en Martínez Hernández, 2004: passim.

48 Una interpretación diversa de esta negociación, en Álvarez de Toledo, 1985, tomo I: 147-155.

49 Thompson, 1969: 211. Según J.A. Escudero, Vázquez estuvo junto al rey todo el tiempo que duró la estancia de Felipe II en Portugal, entre diciembre de 1580 y abril de 1583 . En Escudero, 2002: 230.

50 Hijo del emperador Maximiliano, Alberto de Austria se mantuvo en el virreinato de Portugal hasta 1593, acumulando los títulos de virrey, Inquisidor General y legado del Papa. Ver Martínez Millán y de Carlos Morales, 1998: 318.

51 Lisboa, 31 de diciembre de 1581, ADMS, leg. 2.398. 
su candidatura. Por otro lado, al señalar que estaría como en su casa no hacía sino dar por asumido lo importante que para Medina Sidonia era no perder contacto con sus puntos de interés prioritario, entre los que Portugal no parece que fuera entonces sino el menor de los tres que hemos señalado. Aunque no tenemos constancia de cómo evolucionó la negociación, que se produjo de todos modos sobre la respuesta de don Alonso, lo cierto es que tampoco aquella iniciativa cuajó.

Un segundo frente de interés para Medina Sidonia era el refuerzo de su autoridad militar en la zona del Estrecho. A este respecto, la correspondencia a partir de 1581 no deja lugar a dudas: Medina Sidonia veía con muy buenos ojos la idea de aprovechar la coyuntura bélica para reforzar su autoridad por medio de un cargo de concesión regia que reconociese el alto grado de implicación de su Casa y estados en la defensa de la región. Para ello, don Alonso no dejó escapar ocasión de hacer notar la importancia que para el buen cumplimiento del servicio real tendría un respaldo institucional a sus desvelos. Así por ejemplo, ante la necesidad de levantar hombres en el área, Medina Sidonia se quejó amargamente de cómo las ciudades y, sobre todo, otros nobles del área, a los que citaba sin pudor, no le obedecían:

A los duque de Alcalá y Arcos y marqués de Ayamonte escribo en la conformidad que Vuestra Majestad, rogándoles la brevedad y efecto de lo que se les manda. Y de aquí a seis u ocho días enviaré personas que vean el estado que tuviere la leva de gente para avisarlo a Vuestra Majestad puntualmente, aunque ya he dicho cuán mal saben conocer algunos la merced que Vuestra Majestad les hace en mandarles rogándoles y encargándoles. Y así, por lo de hasta aquí, he visto que es menester mandar y aún de verás para que se cumpla. Yo haré lo a mí posible en solicitarlo y avisaré de todo con puntualidad ${ }^{52}$.

De esta forma, acaso entre otras, hizo llegar don Alonso a Felipe II su queja por la poca colaboración que encontraba en el ejercicio de sus tareas, toda vez que sería el propio monarca quien, en 26 de agosto, transmitió a Medina Sidonia las excusas del duque de Alcalá y del marqués de Ayamonte, mientras que Arcos había encontrado la forma de eludir el mando de don Alonso apelando al agravio comparativo que para su Casa representaba recibir órdenes sobre sus vasallos de otro gran señor ${ }^{53}$. Mientras, Medina Sidonia insistía en

52 Borrador de carta del duque a Felipe II, sin fecha, 1581, ADMS, leg. 2.398.

53 En un texto de difícil interpretación por lo escueto, Arcos solicita al rey que hiciese cumplir lo que su hijo «habló a Vuestra Majestad en acerca de que no se daría orden al duque de Medina Sidonia con que yo no mi Casa pudiésemos quedar desfavorecidos, de que ellos [los ministros regios] no han tenido el cuidado que yo espero». 11 de marzo de 1583, BL, Add., 28.344, fols. $34 \mathrm{r}-35 \mathrm{v}$. 
que la presencia de todas las tropas que se concentraban en la región creaba múltiples roces que requerían una autoridad militar con jurisdicción y que fuese capaz de coordinar los ejércitos ${ }^{54}$.

Ahora bien, Medina Sidonia no dejó de ampliar la gama de posibilidades en su disponibilidad a ocupar cargos regios de mayor consideración. En carta a Mateo Vázquez confesaba:

No me tengo por vano [...], más creo que de lo que se me encargare daré buena cuenta en cualquier género de ministerio y oficio. Y para vuestra merced sólo en la comodidad y asiento de mi patria que es ésta, y en la de mis estados, y no tengo más que desear en la tierra para mí sólo, mas por lo que veo y amo a Su Majestad, que es lo que humanamente no se puede encarecer, querría estar siempre cerca, pues para todos casos, como ya lo he dicho a vuestra merced, es bien y forzoso que yo sirva.

Esta carta, escrita desde el palacio del arzobispo de Sevilla, de quien Medina Sidonia decía ser muy deudo, se abría con la referencia a cierto memorial genealógico que Medina Sidonia había remitido a Vázquez con gran contento por que en él se demostraba lo mucho que había servido siempre su Casa a los reyes de Castilla ${ }^{55}$. No parece casual, por otro lado, que el duque se alojase en casa del prelado, teniendo don Alonso un suntuoso palacio en la ciudad, sino que todo indica que presionaba en todos los frentes posibles - incluido el apoyo del arzobispo - para lograr un nombramiento en Andalucía. Tampoco lo es que al día siguiente esté fechada la escritura de compra por parte del duque del cargo de Alférez Mayor de Sevilla, cuya posesión retuvo don Alonso hasta 1598, cuando lo vendió al marqués de la Algaba ${ }^{56}$.

Medina Sidonia insinuaba también su disponibilidad para cumplir un cometido de gran peso sirviendo junto al monarca. Parece claro que el duque tenía en mente una responsabilidad concreta que tenía mucho que ver con el Atlántico al que, literalmente, se abría la casa del duque a través de la puerto de Sanlúcar. De hecho, el comercio atlántico es la tercera de las áreas prioritarias de atención tradicional de los Medina Sidonia a las que hemos aludido, sin duda la principal ${ }^{57}$. Hacia 1582 el duque ya había avanzado algo en este terre-

54 Sirva de ejemplo cierto problema que se produjo entre la marinería de las galeras y de las armadas oceánicas, cuando coincidieron en Sanlúcar a fines del verano de 1581. Felipe II, reconociendo que «pues la dicha armada ha de partir en breve, parece que se podrá excusar con esto el encargar el castigo de ello a vos o otra persona y para que se haga el que convenga en ello haréis hacer la averiguación de lo que pasó y enviárnosla para que se vea». 12 de septiembre de 1581, ADMS, leg. 2.398.

55 Sevilla, 20 de marzo de 1583, BL, Add., 28.370.

56 No sin problemas con el Consejo de Hacienda. 21 de marzo de 1583 y sentencias de 25 de agosto de 1598 y 28 de abril de 1600, ADMS, leg. 948.

57 Las responsabilidades que ya acumulaba iban desde el apresto y despacho de buques 
no, en especial en materias militares. Para la Corona los problemas logísticos que generaba el manejo de las flotas de Indias, sobre todo tras la desviación de competencias fiscales del Consejo de Indias al de Hacienda, hicieron necesaria la presencia en el área de un mando con carácter militar que agilizase y concentrase ciertos trámites en la preparación de las armadas de escolta ${ }^{58}$. Es en el triángulo institucional formado por la Casa de la Contratación, el Consejo de Indias y el Consejo de Hacienda en el que debemos entender las competencias que Medina Sidonia había ido acumulando con el tiempo en materia de mantenimiento, apresto y defensa de tales armadas con destino y procedentes de América. Es significativo del grado de dependencia que el despacho de las mismas tenía respecto del duque de Medina Sidonia ya en 1581 que, cuando don Alonso hubo de ausentarse para entrar en el sur de Portugal, la prontitud con la que se aprestaban los buques se resintió. Así lo reconoció el rey, que agradeció al duque que hubiese enviado por delante a Sevilla, a su regreso, a un hombre de su confianza, don Diego Maldonado, para agilizar dichos trámites ${ }^{59}$. Sin embargo, no es ocioso señalar que, dado que las responsabilidades de don Alonso no respondían a un cargo concreto, la ausencia del duque, por breve que hubiese sido, le obligó a recomponer los vínculos con las demás autoridades sevillanas, labor que facilitó el propio monarca ${ }^{60}$.

Conviene en este punto señalar otros aspectos esenciales de la coyuntura de aquellos años en la administración del comercio atlántico para entender cabalmente las aspiraciones del duque. Por un lado, tras la incorporación portuguesa, la literatura especializada ha detectado una reorganización general de la alta administración regia. En lo que respecta al Consejo de Indias y a la Casa de la Contratación, a poco más de una década de que hubiesen entrado en vigor las ordenanzas emanadas de la visita de Juan de Ovando — que fue más tarde presidente del Consejo de Indias y también, en funciones, de Hacien-

de escolta (ver, por ejemplo, la carta de 4 de enero de 1580 para el despacho de la galeaza Capitana junto a varias fragatas para acudir a recibir a la armada), a la distribución de material, hombres y víveres en las flotas despachadas. Ambos ejemplos son del año 1580, ADMS, leg. 2.398 .

58 Schäfer señalaba esos problemas logísticos en lo referente al envío de naves de contacto, materia de la que Medina Sidonia pasó pronto a ocuparse, pero la observación puede generalizarse al despacho de flotas y armadas. En Schäfer, 2003: 117.

59 Almada, 15 de junio de 1581, ADMS, leg. 2.398.

60 En palabras de Felipe II, afirmaba que «tendré mucho servicio que aviséis de todo lo que os ocurriere y fuere necesario para el buen y breve despacho de la armada. Al presidente y oficiales [de la Casa de la Contratación] y a Francisco Duarte y Diego Flores [generales de las armadas], a los cuales escribimos [encareciéndoles] la correspondencia que en esto es justo que tengan con vos». Almada, 21 de junio de 1581, ADMS, leg. 2.398. 
da-, se agregó en 1579 la figura de un presidente de la Casa de la Contratación, cargo que ocuparían por turno y por espacio de un año los consejeros de Indias y en el cual iba implícito el cometido de ser jueces visitadores del comercio americano ${ }^{61}$. En cuanto al funcionamiento del Consejo propiamente dicho, el conflicto por la administración del imperio americano adoptó en adelante la forma de una crisis de autoridad interna entre los consejeros y la figura del presidente, motivada por la disputa por la provisión de los cargos de Indias ${ }^{62}$. Además, la desviación de la administración de los recursos de Indias al Consejo de Hacienda en la época en la que Ovando ocupó las dos presidencias había enconado los roces en un órgano que se veía repentinamente privado de una parte esencial de su poder. Por otro lado, otra reforma orientada a la obtención de mayores recursos de América por medio de una mayor vigilancia del tráfico indiano, como fue la creación de una presidencia de la Casa de la Contratación, presentaba algunos inconvenientes institucionales en la relación del nuevo cargo con los jueces de la Casa y con el Consejo de Indias. Un tercer asunto de capital importancia fue el pulso, entonces todavía no resuelto, iniciado por la intención de Felipe II de arrendar unidos los dos grandes almojarifazgos sevillanos, Mayor y de Indias, materia que enfrentaba a Indias, el Consulado y el Concejo de Sevilla — que al fin logró alzarse con el arrendamiento de ambas rentas ${ }^{63}$.

En todo este proceso Medina Sidonia fue dando a conocer su opinión a Felipe II a través de su contacto prioritario en la Corte, Mateo Vázquez. En carta al secretario, don Alonso se preciaba de que

en lo demás de las Indias aseguro a vuestra merced que sé lo de ellas tan puntualmente como si lo hubiera andado y asimismo lo que conviene al servicio de Su Majestad para acrecentarlas y mejorar sus tratos, que va de manera lo que a esto toca que yo temo una gran caída y lo de la Casa de la Contratación [que] está con tantos novicios que realmente, faltando ahora Juan Muñoz de Illescas y Francisco Duarte suspendido, no sé cómo ha de correr lo que allí se dispone.

61 La organización institucional básica de la Casa de la Contratación nos es conocida desde los trabajos pioneros de Piernas Hurtado, 1907; Haring, 1939; Schäfer, 2003. Otros trabajos más recientes son los de Cervera Pery, 1997; Cuesta Domingo, 2001. Sin embargo, sólo se ha comenzado a cuestionar a fondo el significado histórico de la institución en fechas muy recientes. Véanse como muestra dos revisiones colectivas recientes: Acosta Rodríguez, González Rodríguez y Vila Vilar, 2003; y VV.AA., 2004 (en especial Bernal, 2003: 129-160).

62 En torno a 1585 se giró una nueva vista al Consejo, 15 años después de haber finalizado la anterior, que había servido de base para la promulgación de las nuevas Ordenanzas del Consejo de 1571. Al parecer no ha sobrevivido documentación de aquella visita. Schäfer, 2003: 142. Ver también Escudero, 2002: 308 y 415-428.

63 Schäfer, 2003: 112 y 120-121; Lorenzo Sanz, 1986: 365-415. 
Lo cierto es que los novatos a los que aludía el duque, como seguramente ya se temía, iban a causar muchos quebraderos de cabeza a su aduana de Sanlúcar en los cuatro años siguientes. De ahí que la insistencia en el servicio de la que hacía gala Medina Sidonia, que abogaba por un proyecto global de defensa del comercio con Indias, no pueda entenderse sin tomar en cuenta la amenaza que se cernía sobre su principal renta: el almojarifazgo de Sanlúcar. Aunque Medina Sidonia se refiere en sus cartas a un memorial que él había enviado - y que no hemos encontrado-, a través de su correspondencia con Mateo Vázquez se infiere que por entonces estaba proponiendo sustituir el sistema de convoyes escoltados para comerciar con Indias por un sistema de áreas marítimas seguras, útil tanto a las rutas portuguesas como a las castellanas, a través de armadas de vigilancia que se irían relevando en la custodia de los buques mercantes. Con ello, aseguraba, se evitaría el fraude en que desembocaba el sistema de galeones que hacían todo el recorrido oceánico ${ }^{64}$.

Por lo demás, la ostentación de sus conocimientos sobre el comercio que hizo el duque no la dictaba sólo la vanidad. Abandonado el proyecto de enviarle a Milán, a principios de 1583, Antonio de Eraso, quien hacía ya más de una década que ocupaba la secretaría del Consejo de Indias ${ }^{65}$, escribió aún desde Lisboa a Medina Sidonia señalándole la «ocasión [que] tiene Vuestra Excelencia para pedir a Su Majestad todo lo que tan bien entendido tiene de las Indias y de la Casa de la Contratación». Eraso, tras recordar al duque las advertencias que en un sentido parecido ya había hecho al duque, le remitió un memorial en el que se señalaban las críticas de las que la Presidencia de la Contratación había sido objeto desde su creación y le pedía que lo anotase con su opinión. Ponderaba el secretario la importancia de la materia, indicando que el imperio americano era el «nervio y fuerza» de la Monarquía, lo que ya de por sí era señalar a la intención fiscal que las posibles reformas tenían. Justificaba lo mucho que se esperaba de la opinión de Medina Sidonia por lo bien que él sabía sacar dinero de dónde lo había, haciendo producir a las fuentes de riqueza. Añadía la importancia que tenía el cuidado de las cosas del gobierno de ultramar para que no padeciesen vejaciones los vasallos de reinos tan lejanos, lo que apunta, por su parte, a la entonces tan debatida cuestión de la provisión de oficios. Tras hacer protesta de falta de ambiciones personales, Eraso concluía exponiendo su opinión sobre las dos cosas que entonces eran más urgentes. Primero, que se escogiese «un gran Presidente para el Consejo, hombre de capa y espada, que sea del Consejo de

643,5 y 20 de octubre y 23 de noviembre de 1580, Instituto Valencia de Juan (IVDJ), caja 27 bis, envío 15, n. $^{\circ} 88$.

65 Escudero, 2002: 308. 
Estado y Guerra y que sepa qué cosas son armadas y despacho de ellas». En segundo lugar, que escogiese Su Majestad al secretario de quien más satisfacción tuviese para que llevase juntas todas las materias, como el propio padre de Eraso había hecho años atrás ${ }^{66}$.

Eraso envió adjunto el citado memorial, que estaba estructurado en puntos para ser anotados por el duque y en el que se tocaban algunos de los temas a los que se refería en su carta. Se trata de un texto muy técnico sobre 16 asuntos críticos de la presidencia de la Casa de la Contratación, entre los que, sin embargo, no figuran las cuestiones de nombramientos, gobierno y administración del Consejo. Por ello, la posdata de Eraso justificaba las noticias ajenas al contenido del memorial que él mismo había introducido en su carta aduciendo que así el duque tendría una base más amplia para discurrir sobre la Presidencia y los jueces de la Contratación. Felipe II, por su parte, acompañó la consulta subsiguiente con un billete en el que sugería a Medina Sidonia que tratase aquellas materias con Antonio de Guevara, a la sazón proveedor general de Andalucía ${ }^{67}$. El 19 de febrero se remitió desde Sanlúcar, sin firma, la respuesta de don Alonso. De entrada, el duque hacía una valoración negativa de la presidencia de la Contratación, ya que no se habían logrado los fines propuestos con su creación, subrayando la pertinencia de las críticas recogidas en el memorial e insistiendo en algunos puntos esenciales, como eran los efectos negativos de ser un cargo añal y la pérdida casi total de protagonismo que habían padecido los jueces de la Contratación frente al presidente. Propugnaba una división de funciones que separase los aspectos de justicia de los de gobierno, por no ser conveniente que cosas tan graves corriesen por una sola persona. La recomendación, por tanto, era que quien ocupase la presidencia fuese de «bastante reputación y experiencia» pero que no tuviese voto en cuestiones de derecho, dejando hacer a los peritos en tales materias. Con ello se lograría también una clarificación de la estructura judicial, quedando la Contratación como tribunal de primera y segunda instancias y el Consejo de Indias como tribunal de apelación para las causas de mayor cuantía. De este modo el presidente de la Contratación podría, como él aconsejaba, no ser consejero ni miembro de otro tribunal superior, sino hombre de capa y espada experto en materia de armadas. Por todo ello apelaba a la obligación regia, ya que, en resumen, «la administración de justicia y hacienda en la Casa de la Contratación de Indias que reside en Sevilla es en gran daño de la conciencia de Su Majestad y de la hacienda de sus súbditos y tratantes».

66 Lisboa, 30 de enero de 1583, ADMS, leg. 2.400.

67 Martínez Millán y Carlos Morales, 1998: 392-393. 
Don Alonso añadió dos escolios ajenos ya al memorial. El primero hacía referencia a la implicación de Sanlúcar de Barrameda y su puerto en los despachos, recomendando que se remitiesen, antes de la partida de las flotas, dos visitadores que asistiesen en aquel puerto a la carga junto con el factor y el proveedor, a lo que se sumaría, 20 días antes de zarpar, una visita del Presidente «porque asista y se vea y entienda si en Sanlúcar se ha cumplido lo que en Sevilla se ha mandado». Además, se debía recoger la obligación de que los mandos militares no se alejasen mucho del puerto de embarque. En segundo lugar, respecto a la Presidencia del Consejo de Indias, Medina Sidonia aconsejó obrar como, a su vez, le había sugerido Eraso, es decir, proveyendo el cargo en «una persona grande de los de su reino», que también fuese de conocida experiencia en el despacho de flotas y armadas, al que se haría consejero de Estado y Guerra. Del mismo modo, sugería la reunificación de las secretarías, como en tiempos de Francisco de Eraso ${ }^{68}$. En septiembre aún se pidió a don Alonso que clarificase su opinión sobre la relación que debía existir entre el presidente de la Casa de la Contratación y el del Consejo de Indias. Así, en conjunto, Medina Sidonia se erigió como defensor del refuerzo de la vigilancia militar en el comercio a Indias ${ }^{69}$, mientras que la referencia a Sanlúcar suponía el reconocimiento de que la ciudad y, en parte también, la corte ducal, actuaban como centro logístico en el área del Atlántico andaluz en lo referente a las armadas de Indias, poniendo de relieve la utilidad que podía tener aprovechar el poder creado por los duques en la desembocadura del Guadalquivir ${ }^{70}$.

Sin embargo, la opinión de Medina Sidonia tuvo réplica por parte del doctor Gómez de Santillán — consejero de Indias entre 1572 y $1586^{71}$ —, quien envió otro memorial al Consejo de Indias - institución que elevó, a partir de aquella información, una consulta al rey- sobre ciertas reformaciones que consideraba oportuno abordar respecto a la salida de las armadas desde Sanlúcar. Santillán cargó contra el sistema entonces vigente de remitir desde Sevilla a Sanlúcar a un juez, al cónsul del comercio y a un escribano para que asistie-

68 El billete de Felipe II de 30 de enero, la respuesta al memorial de 19 de febrero y la nota de Felipe II agradeciendo la respuesta de 13 de marzo de 1583. ADMS, leg. 2.400.

69 Sugería así el duque un castigo ejemplar en el caso descubierto de una urca con mercancías sin registrar de Juan Antonio Corzo. Dos cartas de 17 de septiembre de 1583 en Riba García, 1959: 295-297.

70 Un buen ejemplo es el despacho de información a los generales, tanto a la salida como a la llegada de los convoyes. Así, ante la amenaza de la presencia de una escuadra turca en la zona, se remitieron cartas para los generales Francisco Luxán y don Antonio Manrique (generales de las flotas de Tierra Firme y Nueva España, respectivamente). Cartas de 16 de agosto de 1581, ADMS, leg. 2.398.

71 Martínez Millán, 1992: 188. 
sen al despacho de las flotas cada vez que se iniciaba un viaje, sobre todo por el costo en sueldos, proponiendo que se encomendase a uno de los escribanos propios de la Casa de la Contratación, que no precisaría sueldo aparte ${ }^{72}$. El Consejo repuso que tal reforma no procedía, al ser oficios de naturaleza diversa las escribanías para el despacho de armadas, por un lado, y para las flotas comerciales, por otro, opinión con la que el rey se conformó, añadiendo que siempre que se pudiera fuese el titular de la escribanía de armadas el que se desplazase a Sanlúcar. Según se desprende de lo dicho, parece que el Consejo frustró así lo que venía a ser un intento de extensión de las competencias de la Contratación en detrimento de la avería, materia en la que tendió a intervenir el Consejo de Guerra. La consulta de Hacienda, por su parte, también advertía de que para evitar encubrimientos de lo que venía sin registrar convendría que en Sanlúcar «hubiese persona de confianza al tiempo de la venida de las flotas para que las visitase», haciéndose eco de las suspicacias sobre el control fiscal en Sanlúcar. Felipe II se conformó con la opinión de Santillán en este asunto, sin dar más especificaciones de cómo ni cuando se proveería dicho cargo ${ }^{73}$.

Las reformas de la Casa de la Contratación que, de hecho, se pusieron en práctica en 1583 coinciden en algunos puntos esenciales con el contenido del memorial del duque, en especial la discriminación en salas de gobierno y justicia unidas en la figura del presidente y la exclusividad que se reconocía a esta institución en lo tocante al apresto de armadas ${ }^{74}$. Así las cosas, tal vez porque el rey estimase por entonces que la persona de confianza que se precisaba podía ser el propio Medina Sidonia, lo cierto es que 1583 representó un aumento bastante importante de la implicación de Medina Sidonia en los despachos de las armadas de Indias. La excusa la proporcionó el hecho de que aquel año algunos grandes mercaderes - entre ellos el prior y cónsules- estuviesen estorbando la formación de una flota con destino a Indias. Según denunció Francisco Duarte - uno de los encargados aquel año de formar la armada - la causa de aquella obstrucción era doble: por una parte, el Consulado pretendía dañar el arrendamiento del almojarifazgo que acababa de tomar la ciudad de Sevilla, mientras que los comerciantes matriculados se beneficiaban de la subida de

$72 \mathrm{Al}$ parecer, aunque tenía señalado un sueldo de tres ducados diarios, la costumbre era subirlo a cinco, pese a los intentos de evitar los excesos por el Consejo de Indias. En 1592 se volvió a consultar sobre el sueldo de estos jueces, considerado corto entonces por el Consejo de Indias, siendo al fin resuelto en 1596 que cobrasen un suplemento en concepto de ayudas de costa y premio por el breve despacho. 8 de agosto de 1592 y 6 de junio de 1596, AGI, Ind. 744, n. 4.

7327 de agosto de 1583, AGI, Ind., 740, n. 169.

74 Serrera, 2004: 59. 
precios en Indias, ya que tenían allí grandes cargamentos almacenados, de modo que si no llegaban más serían los únicos disponibles. Ante el daño que esto podría causar a la Real Hacienda, Duarte propuso un arbitrio para crear una flota que recogiese el tesoro real, la cual se formaría mediante el embargo de seis naos que serían artilladas y remitidas a por el tesoro y en las cuales se consentiría el embarque de mercancías con un coste de flete de 30 ducados por tonelada y cuatro de avería ${ }^{75}$.

Así las cosas, Medina Sidonia escribió a Mateo Vázquez la carta que vimos antes, en la que se ofrecía para un cargo. En agosto de 1583, Felipe II escribió al Consejo de Indias en los siguientes términos:

pues este despacho [de la Flota] está cometido a don Francisco Tello, ordénesele que acuda a él y al general [roto] y otros oficiales lo mismo y que se vayan a Sanlúcar. Y porque el duque de Medina Sidonia se halla allí y tiene tanta experiencia de las cosas de esta calidad, y con su mucho cuidado y diligencia dará gran calor a que se haga brevemente lo que se pretende, como se ha visto por experiencia, para que la dicha flota salga a buen tiempo para volver el año que viene con la de Nueva España, he pensado que convendrá, para que se gane tiempo, que se le encargue la superintendencia de este despacho, escribiéndole que por servirme trate de él y de encaminarle, proveyendo y ordenando desde luego lo que le pareciere conviene ${ }^{76}$.

El 28 de ese mes se hizo efectivo el nombramiento del duque como superintendente para el despacho de la flota, responsabilidad destinada a tener varias réplicas en los años siguientes ${ }^{77}$. Esta ocupación situaba expresamente a todos los implicados en el despacho de las flotas bajo la autoridad del duque, elemento que merece ser destacado sobre todo a la luz de la causa aducida por Felipe II: la eficacia. En cambio, la Casa de la Contratación se mostró algo remisa en acatar las disposiciones del duque, sobre todo en lo tocante a la elección de buques y a su apresto, por lo que el rey hubo de reconvenirles y recordar que debían cumplir lo ordenado por Medina Sidonia ${ }^{78}$.

Felipe II y el Consejo de Indias quedaron bastante satisfechos del trabajo del duque y Duarte, conformándose el Consejo con prorrogar y extender el poder del duque, a quien debían acudir para recibir órdenes los generales y almi-

75 Sin fecha, de 1583, AGI, Ind., 740, n. 158-2.

7617 de agosto de 1583, AGI, Ind., 740, N162, C (la cursiva es nuestra). El nombramiento se hizo oficial el 28 de agosto. AGI, Ind., 1.956, 3-1, 202r-203r.

77 Habían precedido informes de Medina Sidonia sobre la flota de Nueva España de 1583. 8 de mayo de 1583, BL, 28.370, 95r-96v. Otras superintendencias le fueron encomendadas en 1586, cuando fue nombrado para el despacho de la flota a Nueva España en 11 de mayo (AGI, Ind., 1.957, 11, fols. 61r-61v) y para el de Tierra Firme en 9 de junio (Idem, fols. 72r-72v).

78 Así escribió a la Casa y en particular al presidente, el doctor Santillán. 1 y 14 de octubre de 1583, AGI, Ind., 1.956, 3-1, 213r-215v. 
rantes de las armadas. Así, el rey dispuso que, al regreso de Indias de las naos con la plata, aprovechando que don Francisco Duarte estaba en Sanlúcar «entendiendo en los oro y plata y mercaderías que se han de descargar de los navíos que ha elegido el duque de Medina [Sidonia]» ambos debían ir disponiendo la siguiente expedición ${ }^{79}$. La única limitación a la supervisión del duque provino de la forma en la que se debían hacer las compras de bastimentos, que quedaban encargadas al factor, «porque por los inconvenientes que de esto han resultado antes, he ordenado y mandado que sea con intervención del presidente y jueces oficiales [de la Contratación]». Debía responderse así al duque en esta conformidad ${ }^{80}$.

No obstante, la superintendencia no era la meta ambicionada por Medina Sidonia. Como vimos en el cruce de memoriales entre Eraso y Medina Sidonia, mientras el secretario se preocupaba por la presidencia y secretaría de Indias, don Alonso describía sus propias características al retratar al candidato ideal para la presidencia de la Contratación. Antes de acabar agosto, el duque solicitó permiso para acudir a la Corte con la excusa de resolver sus pleitos. Esta vez recurrió a Zayas, a la sazón secretario del Consejo de Italia, al que pidió que mediase para obtener el permiso real o, cuando menos, para que le ayudase a buscar una solución intermedia que le permitiera hacer notar su presencia en Madrid. Según sus palabras,

yo tengo en esa Corte negocios que me son de mucho momento y están parados y aún desesperados. Y como vuestra merced sabe, Su Majestad no me da licencia para que acuda a ellos. No la pido ahora, más conviéneme mucho que Su Majestad me hiciese merced de mandar se me señalase una posada para que, con la sombra de esperarme en ese puesto, pudiese yo desde acá tomar asiento o resolución en mis cosas. Impórtame mucho que Su Majestad me haga esta merced, que si ya se reparare en que no usa ni acostumbra dar posada a nadie, sino a quien es criado, no sé yo quien lo sea tanto de Su Majestad que tan ordinario le sirva, que aunque las cosas [que me encomienda] sean fáciles y cualquier otro podría darse mejor maña en ellas, en fin se camina adelante sin que haya habido yerro ni tropezón en $\operatorname{cosa}^{81}$.

Ciertas minutas entre Zayas y Vázquez sugieren que por entonces ambos favorecían en efecto al duque. Así, mientras Felipe II regresaba desde Lisboa a Madrid, Zayas — que entonces no se encontraba junto al rey- recibió otra carta de Medina Sidonia, sobre cuyo contenido informó a Mateo Vázquez, agregando su juicio al decir que «por cierto tiene [el duque] bien merecido

7920 de septiembre de 1583, AGI, Ind., 740, n. 182.

8022 de septiembre de 1583, AGI, Ind., 740, n. 184-1.

81 Sanlúcar, 25 de agosto de 1583, BL, Add., 28.344, 340r-340v. 
este favor ${ }^{82}$. Todo esto pone de manifiesto que Medina Sidonia administraba su ausencia de la Corte como un elemento más de la negociación con las diversas instancias de decisión cortesanas, tanto los Consejos como los tribunales. Por su parte, el rey dio acuse de recibo de las diversas peticiones de don Alonso para que se tuviese en cuenta su justicia, tranquilizando a don Alonso sobre la atención que se tendría a sus méritos. De todos modos, el rey afirmaba que no podía concederle el permiso para acudir a Madrid, «especialmente con lo que ahí se ofrece en que me servís, por ser cosas que no sufrirán por ahora vuestra ausencia por la mucha satisfacción que yo tengo de vos» ${ }^{83}$.

Así las cosas, ya que Medina Sidonia no podía hacer acto de presencia en la Corte, debían ser sus contactos los que negociasen en su nombre ${ }^{84}$. En carta al duque, Mateo Vázquez afirmaba que

con mucho cuidado se va mirando en el apuntamiento de lo que toca a la Casa de la Contratación y lo demás que en él Vuestra Excelencia dice. Y el grande para la presidencia de Indias bien sé yo cuál sería muy bueno. Su Majestad, con su gran prudencia, lo considerará todo como es menester.

Vázquez añadía todavía un ex curso más o menos erudito sobre la vanitas, comentando una referencia previa del duque alusiva a su amor por la vida retirada y su «menosprecio de lo temporal», para concluir diciendo que

pluguiese a Dios que yo viere por acá a Vuestra Excelencia para poder gozar del favor que para mí sería tratar de estas cosas con Vuestra Excelencia y de otros muchos [asuntos] que se ofrecen en este valle de lágrimas. Y lo importante (ya que se haya de andar algún tiempo en esta plaza del mundo) es procurar hallar en ella el yermo ${ }^{85}$.

Más allá de la recreación del tópico contemplativo, las referencias al deseo de ver a Medina Sidonia en Madrid deben ser interpretadas como una clara alusión a que se estaba trabajando por la candidatura de don Alonso para la presidencia no ya de la Casa de la Contratación, sino del mismísimo Consejo de Indias ${ }^{86}$. Ese yermo del mundo sería entonces para el duque un puesto de la máxima responsabilidad en el comercio americano junto al monarca y no en Sanlúcar o Sevilla. Como muy bien sabían el duque y el secretario, poner a la cabeza del Consejo no a un letrado, sino a un noble militar implicaba dar un

8230 de diciembre de 1583, BL, Add., 28.344, 347r-262v. Otras cartas de aquellas mismas fechas insistían en la petición del permiso, BL, $A d d$, 28.370, fols. 141r-144v.

835 de noviembre de 1583 , BL, $A d d, 28.358$, fols. $270 \mathrm{r}-271 \mathrm{v}$.

84 Permiso que se le negó hasta 1585, cuando al fin acudió en efecto a la Corte. Álvarez de Toledo, 1985: 71.

85 San Lorenzo, 5 de noviembre de 1583, ADMS, leg. 2.400.

86 Idea que coincide con la respuesta recogida por Lovett, 1977: 150. 
giro al significado mismo de la institución. El pulso por el control del tráfico americano, a esas alturas del siglo XVI muy enconado, entre la Casa de la Contratación y el Consulado, hubiera tenido así en este punto otro escenario ${ }^{87}$.

Por su parte, Medina Sidonia se encontraba ahora ante la posibilidad de modificar sustancialmente su estrategia de poder, pero manteniendo el fuerte contacto con sus intereses territoriales que significaba seguir ocupándose de las cuestiones americanas. Aunque no tenemos constancia de su respuesta, podemos conjeturar, a la vista de sus ofrecimientos de servir junto al rey, que la presidencia de Indias no quedaba precisamente fuera de sus expectativas. Al año siguiente, cuando parecía que se iba enfriando la candidatura del duque para ninguna de las dos presidencias, Vázquez recordó a Medina Sidonia, buscando demostrar lo mucho que le servía, que él había sido uno de los que más trabajó para traerle a la Corte ${ }^{88}$. Pero lo cierto es que de entre las filas de los altos mandos militares surgieron voces críticas contra Medina Sidonia. En septiembre de 1583 don Alonso escribió muy irritado a Mateo Vázquez, lamentando los roces que estaba teniendo con el marqués de Santa Cruz y con don Pedro de Leyva. De este último decía que «hace burla de que yo ande ocupado en estas flotas y despacho de barcos, y ésta es la plática que anda mofando y haciendo lo que él no se atreviera si yo no hubiera dado la palabra a Su Majestad», palabra que consistía en procurar tener buena correspondencia con ambos. Pedía a Vázquez que le comunicase a Su Majestad que «quien tiene su honra tan aventurada y aún maltratada, que no puede dejar de volver por ella, pues con la vida y alma y hacienda yo le sirvo y serviré como lo hago, mas que faltándome honra no puedo dejar de volver por ella como me convenga, sin que se pase más de lo de hasta aquí, que ha sido un gran daño en mis cosas». Acusaba de paso a Santa Cruz de haber gastado demasiado en su expedición a las islas Terceras ${ }^{89}$. Al parecer, el objeto de la burla era cierta propuesta del duque de Medina Sidonia al rey de enviar negros de Angola a América para beneficiar las minas y financiar al mismo tiempo la propia Carrera de Indias ${ }^{90}$. Vázquez, por su parte, mostró su apoyo al duque, afirmando que aquellas cosas «no conviene tengan lugar, ni que tampoco le tengan malos oficios, que tanto se usan en el mundo para inquietar, y las más veces sin culpa ni ocasión de las partes principales ${ }^{91}$. Pese a que el origen de esta disputa no parece ha-

87 Oliva Melgar, 2003; 449.

88 San Lorenzo, 30 de mayo de 1584, ADMS, leg. 2.400.

89 Sanlúcar, 16 de septiembre de 1583, BL, Add. 28.370, 111r-113v. Al parecer se recurrió a Juan Martínez Recalde para calmar los ánimos.

90 Riba García, 1959: 295-296.

918 de octubre de 1583, BL, Add. 28.370, 262r-262v. 
ber sido propiamente militar, y pese a la corta vida que la misma controversia tuvo, lo cierto es que derivó en unas acusaciones que perjudicaron las aspiraciones de don Alonso ${ }^{92}$.

\section{CONCLUSIÓN}

Al fin, el proyecto de dar entrada en la administración indiana a un grande fue, por el momento, suspendido. Según nuestra interpretación, los argumentos que subyacen al proceso de negociación que hemos descrito en estas páginas oscilaban entre dos impulsos enfrentados que, en aquella coyuntura, resultaron decisivos. Por una parte, optar por dar un perfil más aristocrático a la dirección del comercio oceánico - a través de la elección del duque don Alonso para la presidencia del Consejo de Indias - hubiera supuesto dar prioridad a los aspectos defensivos de la Carrera y compensar, en parte, al Consejo por la retirada de competencias fiscales que se había producido a favor de Hacienda, trasvase que, a su vez, estuvo guiado por el afán de alcanzar una mayor pulcritud fiscal en la gestión de los caudales de Indias. Del mismo modo, visto en perspectiva, si la creación de la presidencia de la Casa de la Contratación fue en sí misma un intento de atajar la pérdida de protagonismo de esta institución, elegir a Medina Sidonia hubiera supuesto dar un fuerte espaldarazo a dicha iniciativa, precisamente por la combinación de autoridad y poder que ofrecía el duque en la Baja Andalucía, Sevilla incluida. En otras palabras, en el trasfondo de la candidatura del duque a las dos presidencias figuraba, por tanto, la baza de ofrecerse para detener el ocaso que en la gestión de la Carrera de Indias estaba padeciendo el bloque institucional Consejo de Indias-Contratación, que ya entonces se percibía con claridad, y cuyas causas encontramos en el imparable crecimiento institucional del Consulado de Sevilla y en la extensión de competencias del Consejo de Hacienda en la Corte ${ }^{93}$.

Esta idea se ve reforzada si atendemos a los argumentos contrarios y a las resistencias a los que se enfrentó el duque. En primer lugar, por lo que respecta a la Presidencia de Indias, la opción por un noble - es decir, por un ministro de capa y espada - no debió ser muy bien vista por los propios consejeros de dicho organismo, que estaban empeñados por entonces en una lucha por de-

92 Las denuncias en un resumen de carta de Medina Sidonia a Mateo Vázquez de 6 de noviembre y carta del mismo al mismo de 16 de diciembre de 1583 , ya en tono conciliador. BL, Add. $28.370,127 \mathrm{r}-128 \mathrm{v}$ y $139 \mathrm{r}-140 \mathrm{v}$.

93 Schäfer señala un lapso sin presidencia del Consejo de Indias entre el 6 de noviembre de 1580 y el 19 de junio de 1584, atribuyéndolo a un «método de economía bastante extraño», en Schäfer, 2003: 121, 334 (Apéndice I). Sobre todo, ver Oliva Melgar, 2001; 454-456. 
fender su parcela de poder en la institución, la cual se hubiera visto amenazada por la figura de un presidente de corte presumiblemente autoritario. Pero sobre todo, en segundo lugar, poco favorecían la causa de Medina Sidonia las acusaciones de fraude que en aquel momento se estaban vertiendo contra los ministros de su aduana en Sanlúcar. En efecto, las grandes visitas que a la sazón se estaban girando en las diversas aduanas de la Baja Andalucía pusieron de manifiesto la divergencia de criterios que enfrentaba al duque con el Consejo de Hacienda ${ }^{94}$. Así, atendiendo a los informes de los visitadores, optar por el énfasis en la persecución del fraude parecía difícilmente compatible con dar nuevo protagonismo al duque.

En todo caso, cuando al fin se proveyó la presidencia del Consejo de Indias en 1584, se optó por situar a un letrado al frente de la institución. La derrota política del duque - pese a sus méritos en el servicio regio plasmados en su participación en la crisis portuguesa - supuso, en fin, el fracaso relativo de una estrategia basada en la intervención institucional sobre el comercio de Indias. Sólo relativo porque, de hecho, don Alonso mantuvo durante algunos años las superintendencias sobre las armadas que ocasionalmente se le encomendaron. Además, Medina Sidonia alcanzó por este medio una de sus máximas ambiciones, que era la de mantenerse ocupado en el servicio real sin abandonar su palacio sanluqueño, algo que indudablemente reforzaba aún más su autoridad. De hecho, el resultado fue que en pocos años Medina Sidonia consiguió implicar de tal forma su Casa y señorío en la defensa de la Baja Andalucía - incluida la seguridad de las flotas de Indias- que ya en 1588, con motivo de su mando sobre la llamada Armada Invencible, obtuvo al fin un cargo estable con competencias sobre su zona prioritaria de interés: la Capitanía General del Mar Océano y Costas de Andalucía.

\section{BIBLIOGRAFÍA}

Acosta Rodríguez, Antonio, González Rodríguez, A. y Vila Vilar, E., La Casa de la Contratación y la navegación entre España y las Indias, Sevilla, 2003.

Álvarez de Toledo, L. I., Alonso Pérez de Guzmán, general de la Invencible, 2 tomos, Cádiz, 1985.

Álvarez-Ossorio Alvariño, A., Milán y el legado de Felipe II: gobernadores y corte provincial en la Lombardía de los Austrias, Madrid, 2001.

Bennassar, B. y L., Los cristianos de Alá. La fascinante aventura de los renegados, Madrid, 1989.

94 Salas Almela, 64-2 (Sevilla, 2007): 13-60. 
Bernal, A. M., «La Casa de la Contratación de Indias: del monopolio a la negociación mercantil privada (siglo XVI)», Antonio Acosta Rodríguez, A. González Rodríguez y E. Vila Vilar, La Casa de la Contratación y la navegación entre España y las Indias, Sevilla, 2003: 129-160.

Bouza, Fernando, Imagen y propaganda. Capítulos de historia cultural del reinado de Felipe II, Madrid, 1998.

Bouza, Fernando, Portugal no tempo dos Felipes. Política, cultura, representações (1580-1668), Lisboa, 2000.

Cabanelas, D., «El problema de Larche en tiempos de Felipe II», Miscelánea de Estudios Árabes y Hebraicos, IX (1960): 19-53.

Cabanelas, D., «El duque de Medina Sidonia y las relaciones entre Marruecos y España en tiempos de Felipe II», Miscelánea de Estudios Árabes y Hebraicos, XXIII (1974): 7-27.

Cervera Pery, J., La Casa de la Contratación y el Consejo de Indias (Las razones de un superministerio), Ministerio de Defensa, Madrid, 1997.

Cuesta Domingo, M., «La Casa de la Contratación», VV.AA., La Casa de la Contratación de Sevilla. Aproximación a un centenario (1503-2003), Instituto de Historia Naval, Madrid, 2001: 9-42.

Escudero, J. A., Felipe II. El rey en el despacho, Madrid, 2002.

Fernández Álvarez, M., «La España de Felipe II (1527-1589). Auge y declive de un Imperio (1566-1598)», José María Jover Zamora (dir.), Historia de España Menéndez Pidal, tomo XXII/4, Madrid, 2002.

Haring, C., Comercio y navegación entre España y las Indias, México, 1939 [1918].

Kamen, H., Felipe de España, Madrid, 1998.

Lovett, A. W., Philip II and Mateo Vázquez de Leca: the Government of Spain (1572-1592), Ginebra, 1977.

Martínez Hernández, S., El marqués de Velada y la Corte en los reinados de Felipe II y Felipe III. Nobleza cortesana y cultura política en la España del siglo de Oro, Valladolid, 2004.

Martínez Millán, J., «Grupos de poder en la Corte durante el reinado de Felipe II: la facción ebolista, 1554-1573», J. Martínez Millán (ed.): Instituciones y elites de poder en la Monarquía Hispana durante el siglo XVI, Madrid, 1992: 137-197

Martínez Millán, J. y De Carlos Morales, C. J. de (dirs.), Felipe II (1527-1598). La configuración de la Monarquía Hispánica, Valladolid, 1998.

Oliva Melgar, J. M., «Pacto fiscal y eclipse de la contratación en el siglo XVII: Consulado, Corona e indultos en el monopolio de Indias», Antonio Acosta Rodríguez, A. González Rodríguez y E. Vila Vilar, La Casa de la Contratación y la navegación entre España y las Indias, Sevilla, 2003: 449-493.

Piernas Hurtado, J., La Casa de la Contratación de las Indias, Madrid, 1907. 
Riba García, C., Correspondencia privada de Felipe II con su secretario Mateo Vázquez, Madrid, 1959.

Rodríguez Salgado, M. J., Un Imperio en transición. Carlos V, Felipe II y su mundo, Barcelona, 1992 (1988).

Salas Almela, L., Colaboración y conflicto. La capitanía general del Mar Océano y Costas de Andalucía, 1588-1660, Córdoba, 2002.

Salas Almela, L., «Nobleza y fiscalidad en la ruta de las Indias: el emporio señorial de Sanlúcar de Barrameda (1576-1641)», Anuario de Estudios Hispano-Americanos, 64-2 (Sevilla, 2007): 13-60.

Salas Almela, L., Medina Sidonia. El poder de la aristocracia (1580-1670), Madrid, 2008.

Sancho de Sopranis, H., «Cádiz y la piratería turco-berberisca en el siglo XVI», Archivo del Instituto de Estudios Africanos, 26 (1953): 7-77.

Serrera, R. M., «La Casa de la Contratación en Sevilla (1503-1717)», VV.AA., España y América. Un océano de negocios. Quinto centenario de la Casa de la Contratación, 1503-2003, Madrid, 2003: 47-64.

Schäfer, H., El Consejo real y supremo de las Indias. Historia y organización del Consejo y de la Casa de la Contratación de las Indias, 2 vols., Valladolid, 2003 (1935).

Thompson, I. A. A., «The Appointment of the Duke of Medina Sidonia to the Command of the Spanish Armada», The Historical Journal, 12-2 (1969): 197-216.

VV.AA., España y América. Un océano de negocios. Quinto centenario de la Casa de la Contratación, 1503-2003, Madrid, 2003.

Fecha de recepción: 12-3-2007

Fecha de aceptación: 18-9-2007

\section{A POST FOR THE DUKE OF MEDINA SIDONIA: PORTUGAL, THE GIBRALTAR STRAITS, AND LATIN AMERICAN COMMERCE, 1578 - 1584}

This article reveals and interprets the negotiations surrounding the nomination around 1580 of the Duke of Medina Sidonia as a candidate for the presidency of both the Consejo de Indias and the Casa de la Contratación. The historical context of those years, both that of the ducal house and that of the crown and its institutions, provide relevant clues regarding the contemporary debate about the duke's suitability as a candidate for both posts. In turn, the duke's refusal of these posts also sheds important light on the significance of this crucial historical juncture.

KeY words: Nobility, defence, power, Carrera de Indias, institutions, armies. 